\title{
The Eradication Rate of Levofloxacin containing Quadruple therapy for the First-Line treatment of Helicobacter Pylori
}

\author{
Tran Thi Khanh Tuong* \\ Department of Internal Medicine, Pham Ngoc Thach University of Medicine, Vietnam \\ *Corresponding author: Tran Thi Khanh Tuong, Department of Internal Medicine, Pham Ngoc Thach University of Med- \\ icine, 02 Duong Quang Trung, District 10, Ho Chi Minh city, Vietnam
}

ARTICLE INFO

Received: 慧 April 04, 2020

Published: April 20, 2020

Citation: Tran Thi Khanh Tuong. The Eradication Rate of Levofloxacin containing Quadruple therapy for the First-Line treatment of Helicobacter Pylori. Biomed J Sci \& Tech Res 27(1)-2020. BJSTR. MS.ID.004451.

Keywords: Levoflocaxin containing quadruple regimen; Eradication; Helicobacter pylori infection

\begin{abstract}
Background: Some studies have shown efficacy of levofloxacin containing quadruple therapy for the first-line treatment of $H$. pylori, especially in regions of high clarithromycin, metronidazole, and levofloxacin resistance. There have been no studies about the efficacy of levofloxacin-containing quadruple therapy for the first-line treatment of $H$. pylori infection.
\end{abstract}

Methods: A total of 98 naïve patients with H. pylori infection received a levofloxacin containing quadruple therapy, RBAL (rabeprazole $20 \mathrm{mg}$, b.i.d., bismuth subsalicylate $525 \mathrm{mg}$, b.i.d., amoxicillin $1 \mathrm{~g}$, b.i.d, levofloxacin $500 \mathrm{mg}$, once daily). The primary outcome was the eradication rate in the intention-to-treat (ITT) and per protocol (PP) analysis.

Results: The eradication rates of the levofloxacin containing quadruple therapy using PP analysis were $92.7 \% \%$, and $89.9 \%$, using ITT analysis $(\mathrm{p}<0.05)$. Side effects occurred in patients (38.2\%), but not serious. The compliance rate more than $90 \%$ of the levofloxacin-based quadruple therapy was $89.9 \%$.

Conclusion: Efficacy of levofloxacin containing quadruple regimen was high with mild side effects and high medication adherence. Hence, this regimen should be considered the first-line therapy for $H$. pylori infection.

\section{Introduction}

Treatment for $H$. pylori infection still challenges. Despite early successes, clarithromycin triple therapy and levofloxacin triple therapy regimens are not very effective at eradicating H pylori [1], due to an increase in antibiotic resistance of H. pylori, specifically clarithromycin, metronidazole and levofloxacin. In our country, the resistance to these three antibiotics is very high, respectively $42.4 \%$, $76.1 \%$ and $41.3 \%$ [2]. In areas with high rates of clarithromycin and metronidazole resistance in our country ( $>15 \%)$, the 4-drug regimen with bismuth and the 3-drug regimen containing levofloxacin is recommended by most guidelines in the world as a first-line regimen. first. However, the bismuth 4-drug regimen has many side effects and the effectiveness of the 3-drug regimen containing levofloxacin is not high. Recently, several studies have shown that a levofloxacin triple therapy regimen combined with bismuth (a four-drug regimen containing levofloxacin) increases the efficacy of H.pylori eradication for the first time in a triple-drug regimen with levofloxacin $[3,4]$. There are no studies evaluating the effectiveness of levofloxacin 4-drug regimens for the first treatment of H.pylori infection in our country. Therefore, we carry out this study with the following objectives: $H$. pylori eradication rate of levofloxacin 4-drug regimen, and incidence of side effects and treatment adherence of a 4-drug regimen containing levofloxacin

\section{Material and Methods}

Patients (patients) diagnosed with H. pylori infection are indicated for treatment and have not been previously treated at 
the gastroenterology clinic of the University Hospital of Medicine and Pharmacy at Ho Chi Minh City University of Medicine and Medical University Clinic Faculty Pham Ngoc Thach Ho Chi Minh City. Sampling criteria: Patients 18 years of age and older diagnosed with $H$. pylori infection, who have never been treated before, using either of the following two methods: Fastest urease (CLO test) positive -Test breath C13 (C13 urea-breath test) positive Exclusion criteria - Stomach cancer (diagnosed with endoscopy with or without pathology) - Severe medical conditions: decompensated cirrhosis, end-stage chronic kidney disease, severe heart failure, COPD ... - Patients are using antibiotics other than those included in the study regimen - Patients do not follow-up examination as designed - Pregnant or lactating women. All patients treated with RBAL regimens for 14 days included: rabeprazole (Pariet) $20 \mathrm{mg}$ twice daily, 30 to 60 minutes, levofloxacin (Tavanic) $500 \mathrm{mg} /$ day, amoxicillin $1000 \mathrm{mg}$ twice daily, bismuth subsalicylate ( Ulcersep $262.5 \mathrm{mg}$ ) or colloidal bismuth subcitrate $120 \mathrm{mg}$ (Trymo 120mg) 2 capsules twice daily.

Monitor and check for H. pylori after treatment: Patients are reexamined after 2-4 weeks to evaluate side effects and adherence. Check H. pylori infection status after 4-8 weeks of treatment with rapid urease test (CLO test) or $\mathrm{C} 13$ breath test (C13 urea-breath test). The patient did not take any other antibiotic or bismuth for at least 4 weeks, proton pump inhibitor for at least 2 weeks and $\mathrm{H} 2$ receptor antagonist for at least 1 week before re-checking for $H$. pylori infection. Compliance assessment: $<50 \%$ of nonconforming drugs were excluded from the study, $50-<80 \%$ poor compliance, $\geq 80 \%$ of good adherence, patients with compliance $\geq 80 \%$ were classified as subgroup. analysis according to research design (PP). Data was analyzed using software of Stata $12, \mathrm{p}<0.05$ is statistically significant. Use the $\chi 2$ test or calibrate Yate's to compare 2 ratios. Compare 2 averages by t test.

\section{Results}

Table 1: Study population characteristics.

\begin{tabular}{|c|c|c|}
\hline Characteristics & N & \% \\
\hline Male & 48 & 53,9 \\
\hline Age & 42,24 & 13,19 \\
\hline Smoking habit & 15 & 16,9 \\
\hline Drinking habit & 21 & 23,5 \\
\hline Using NSAIDs & 12 & 13,5 \\
\hline
\end{tabular}

Between January 2019 and July 2019, we collected 89 previously untreated H. pylori infections (Table 1). 89 patients were tested to confirm H.pylori eradication were included in the researchoriented analysis (ITT) and the research design (PP). 07 patients who received treatment $<80 \%$ or re-examined not according to the study design or taking additional antibiotics other than the prescribed drug, were excluded from PP analysis. Thus, 82 patients were analysed according to ITT. H. pylori eradication rates for ITT and PP analysis were both high (Table 2). Black feces is the most serious side effect, most side effects are mild and no patient has to discontinue the drug due to side effects (Table 3). The compliance rate $\geq 90 \%$ accounts for the highest rate (Table 4 ).

Table 2: H. pylori eradication effect.

\begin{tabular}{|c|c|c|c|}
\hline & $\mathbf{N}$ & $\mathbf{n} / \mathbf{N}(\%)$ & $\mathbf{P}$ \\
\hline $\begin{array}{c}\text { According to } \\
\text { ITT }\end{array}$ & 89 & $81 / 89(89,9)$ & \multirow{2}{*}{$<0,05$} \\
\hline According to PP & 82 & $76 / 82(92,7)$ & \\
\hline
\end{tabular}

Table 3: Side effects of the regimen.

\begin{tabular}{|c|c|c|}
\hline Side effects & N & \% \\
\hline Tired & 22 & 24,7 \\
\hline Nausea & 21 & 23,6 \\
\hline Dizzy & 18 & 20,2 \\
\hline Constipation & 17 & 19,1 \\
\hline Diarrhea & 19 & 21,3 \\
\hline Black stool & 41 & 46,1 \\
\hline Difficulty sleeping & 25 & 28,1 \\
\hline Headache & 12 & 13,5 \\
\hline $\begin{array}{c}\text { Discontinue the drug due to side } \\
\text { effects }\end{array}$ & 0 & 0 \\
\hline $\begin{array}{c}\text { Total number of patients with } \\
\text { side effects }\end{array}$ & $34 / 89$ & 38,2 \\
\hline
\end{tabular}

Table 4: Compliance of the regimen.

\begin{tabular}{|c|c|c|}
\hline Compliance level & $\mathbf{N}$ & $\mathbf{\%}$ \\
\hline $50-<80 \%$ & 03 & 3,4 \\
\hline $80 \%-90 \%$ & 06 & 6,7 \\
\hline$\geq 90 \%$ & 80 & 89,9 \\
\hline Total & 89 & 100 \\
\hline
\end{tabular}

\section{Discussion}

Recent meta-analysis studies show that the use of a tripledrug regimen containing levofloxacin as a first or relatively low eradication [5]. According to this study, the 3-drug regimen containing levofloxacin has a very low $H$. pylori eradication rate, according to ITT is $77.3 \%$ and PP is $80.7 \%$. The effectiveness of levofloxacin triple therapy is lower than $80 \%$ in many countries and so the study has concluded that this regimen is not recommended when the levofloxacin resistance rate is $5-10 \%$ higher. Bismuth has a long history of treating $H$. pylori because it works synergistically with antibiotics and reduces bacterial load, so it increases the eradication rate of this bacterium. More importantly, there is no H. pylori resistance to bismuth, making bismuth a preferred antibacterial agent for eradicating $\mathrm{H}$ pylori. Bismuth acts on $H$. pylori through multiple mechanisms [6]: bactericidal by creating complexes on cell walls and cytoplasm; reduces bacterial survival by inhibiting enzymes such as urease, catalase, lipase, phospholipase as well as inhibiting the synthesis of ATP and the adhesion capacity of $\mathrm{H}$. pylori, reducing the bacterial load in the stomach. Therefore, the combination of bismuth for triple therapy with levofloxacin in 
some studies has shown an increase in H. pylori eradication rates for the first time $[3,4]$.

Similarly, in our study, levofloxacin 4-drug regimens had high rates of first $H$. pylori eradication in patients on IIT and PP $(89.9 \%$ and $92.7 \%$ ). Most patients in our study adhered to treatment very well, the proportion of patients who adhered to the drug $\geq 90 \%$ was $88.7 \%$. Most patients have mild side effects that do not affect the course of treatment. The proportion of patients with side effects was $38.2 \%$ with common side effects such as nausea, difficulty sleeping and black stools, no patients complained of tendon pain. Most of these side effects were mild and did not affect patient adherence and no patient had to discontinue treatment due to side effects. Levofloxacin 4-drug regimen is quite simple because it is taken only twice a day, most of the side effects are mild compared to bismuth 4-drug regimen. The 4-drug regimen containing bismuth had to be taken 4 times a day and had more side effects such as Tran Thi Khanh Tuong (2017), the rate of patients with quite high side effects was $80.5 \%$ [7], similar to $Đ$. Resolution $81.93 \%$ [8]. Therefore, the compliance rate of patients $\geq 90 \%$ in these two studies is lower than our study. In addition, carefully advising patients before treatment about the effectiveness, possible side effects of the regimen and advising patients to be encouraged during timely treatment when necessary will help patients adhere to treatment better.

\section{Conclusion}

H.pylori eradication effect of levofloxacin 4-drug regimen is high, side effects are not much and patient compliance is high.

ISSN: 2574-1241

DOI: $10.26717 /$ BJSTR.2020.27.004451

Tran Thi Khanh Tuong. Biomed J Sci \& Tech Res

This work is licensed under Creative Commons Attribution 4.0 License

Submission Link: https://biomedres.us/submit-manuscript.php
Therefore, this regimen should be considered as the first regimen for H.pylori infection.

\section{References}

1. Bui Quang Di, Hoang Trong Thang (2011) Study the effectiveness of Helicobacter pylori eradication with a 3-drug regimen containing Levofloxacine. Vietnam journal of Enterogastrology 12: 370-735.

2. Phan TN, Santona A, Tran VH, Tran TNH, Cappuccinelli P, Rubino S, et al. (2015) High rate of levofloxacin resistance in a background of clarithromycin-and metronidazole-resistant Helicobacter pylori in Vietnam. International journal of antimicrobial agents 45(3): 244-248.

3. Evrim Kahramanoğlu Aksoya FPcS, Zeynep Göktașb Metin, Uzmana Yaşar Nazlıgüla (2017) Comparison of Helicobacter pylori Eradication Rates of 2-Week Levofloxacin-Containing Triple Therapy, LevofloxacinContaining Bismuth Quadruple Therapy, and Standard Bismuth Quadruple Therapy as a First-Line Regimen. Med Princ Pract 26: 523529.

4. Jing Su, Xiaoying Z, Han Chen, Bo Hao, W Zhang, et al. (2017) Efficacy of 1st-line bismuth-containing quadruple therapies with levofloxacin or clarithromycin for the eradication of Helicobacter pylori infection: A 1-week, open-label, randomized trial. Medicine (Baltimore) 97: e5859.

5. Chen PY WM, Chen CY, MJ Bair, CK Chou, et al. (2016) Systematic review with meta-analysis: the efficacy of levofloxacin triple therapy as the first- or second-line treatments of Helicobacter pylori infection. Aliment Pharmacol Ther 44(5): 427-437.

6. Marcus EA, Sachs G, Scott, DR (2015) Colloidal bismuth subcitrate impedes proton entry into Helicobacter pylori and increases the efficacy of growth-dependent antibiotics. Aliment Pharmacol Ther 42(7): 922933.

7. Tran Thi Khanh Tuong (2017) The therapeutic effect of a 4-drug regimen with Bismuth in the treatment of Helicobacter Pylori infection. Vietnam Journal of Gastroenterology 49: 3067-3073.

8. Dang Ngoc Quy Hue, Nguyen Thanh Hai (2017) Chronic gastritis caused by Helicobacter pylori: eradication effect of bismuth quadruple regimen (EBMT). Journal of Medicine and Pharmacy 32: 149-159.

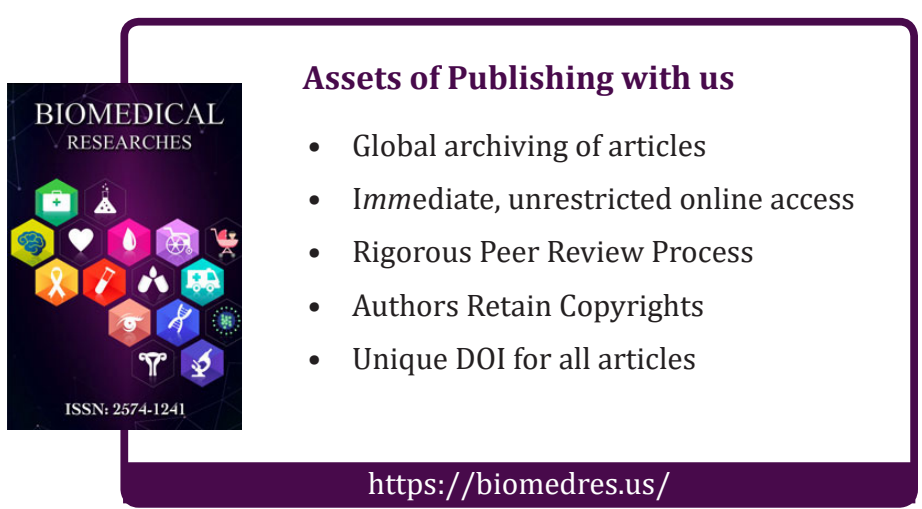

